ORIGINAL ARTICLE

\title{
Efficacy and Safety of Immediate Postpartum Intrauterine Contraceptive Devices in C-Section and Vaginal Deliveries
}

\author{
BUSHRA MEHMOOD ${ }^{1}$, SUMAYYA KHALIQ², SYEDA KHALIDA NAEEM ${ }^{3}$, KHADIJA SAEED $^{4}$, AESHA SADAF RIZWAN ${ }^{5}$ \\ ${ }^{1}$ Assistant Professor Gynae \& Obs department, Shahida Islam Teaching Hospital. Lodhran. \\ ${ }^{2}$ Post Graduate Trainee, Gynae \& Obs department, Services Hospital Lahore \\ ${ }^{3}$ Senior Registrar Gynae \& Obs Makran department, Medical College Turbat/Teaching Hospital, Kech \\ ${ }^{4}$ Consultant Gynaecologist, PAF Hospital, Shorkot Cantt \\ ${ }^{5}$ Assistant Professor, Gynae \& Obs department, Shahida Islam Teaching Hospital, Lodhran.
}

Corresponding Author: Bushra Mehmood, Assistant Professor of Obstetrics \& Gynecology, Shahida Islam Medical College Lodhran. Email, bushramehmood214@gmail.com. Contact \#+92 3346058341

\begin{abstract}
Aim: To determine the safety and efficacy of immediate postpartum intrauterine contraceptive devices insertion after vaginal and caesarean and vaginal deliveries.

Study Design: Retrospective study

Place \& Duration: Conducted at Gyne \& Obs Department, Shahida Islam Teaching Hospital Lodhran, during from 1-06-2020 to 30-06-2021.

Methods: In this study 120 patients were included in this study. Patients' ages were ranging from 20 to 45 years. Patients' detailed medical history including age, residence and socioeconomic status were examined after taking written consent. All the patients divided into two groups, 60 caesarean, 60 vaginal. IPPIUCDs were inserted in all the patients. Outcomes were examined at follow-up and compared between both groups. Data was analyzed by SPSS 24.0. P-value $<0.05$ was considered as significant.

Results: $48(40 \%)$ patients had ages between 20 to 30 years, $56(46.7 \%)$ patients had ages 31 to 40 years and $16(13.3 \%)$ patients had ages above 40 years. Complications rate was low. Perforation and pregnancy rate was $0 \%$. Menstrual disturbance reported in $20(16.7 \%)$ which was significantly higher in vaginal group. Expulsion rate was $9(7.5 \%)$ and significant higher in vaginal group $p<0.05$. Removal was done in $14(11.7 \%)$ cases and rate of removal of IUCD was high in vaginal group. Continuation rate at follow-up was $106(88.3 \%)$.

Conclusion: It is concluded that the insertion of immediate postpartum intrauterine contraceptive devices was effective and safe method with low complications rate.
\end{abstract}

\section{INTRODUCTION}

Pakistan is the world's 6th most populated country. The number of people in a country is inversely linked to its rate of economic growth. The less people there are, the more resources there are available for improving living standards and developing the country. A worldwide birth rate control is not only debated at the highest levels, but tangible actions are also being implemented at the country level to maintain birth rates. [1] Pakistan is working to establish a platform for the promotion and effective use of contraception in order to meet the Sustainable Development Goals (SDGs) by 2030 and promote prosperity for all. In 2012, significant efforts to improve family planning were made. [2,3] Government of Pakistan has created a comprehensive plain for family planning with the assistance of provisional governments to include preparation of contraceptives and training of mid-level service providers in the private and public sectors to deliver intrauterine contraceptive devices and implants. As part of social mobilization, males and religious experts are also being enlisted to help raise social acceptance of family planning. The World Health Organization (WHO) recommends the immediate insertion of an intrauterine contraceptive device (IUCD) as a safe and effective means of temporary contraception [5]. All women who are breastfeeding can safely use the postpartum intracontraceptive uterine device (PPIUCD) to prevent pregnancy. Between $39 \%$ and $65 \%$ of women in the first year after giving birth have unmet family planning needs [5-
7]. Providing contraception during this vulnerable time is so critical. As a cost-effective, reversible, and convenient method of contraception that minimizes the number of abortions, PPIUCD is recommended.

Many unintended pregnancies occur in the first year after giving birth because women resume sexual activity too soon, and ovulation occurs at an uncertain time. Furthermore, particularly in developing countries, women who return home after giving birth do not even return for a standard postpartum check-up, let alone contraceptive methods of contraception. The importance of postpartum family planning services, where a woman is discharged from the hospital with access to contraception, should be highlighted. In-patient deliveries give an exceptional chance to provide postpartum women with a long-acting yet reversible method of contraception. Long-acting reversible contraceptive insertions have been shown in Cochrane reviews to be safe and feasible in many circumstances [89].

When women in low-resource settings give birth in a facility, they are less likely to return for further care, making it an ideal moment to start family planning. Long-acting reversible contraceptives like the PPIUCD encourage women to give birth in a hospital [11, 12] since it is effective. In the postpartum period, LARC offers various advantages due to its effectiveness, coitus independence, and non-interference with breast-feeding.

The purpose of this study aimed to examine the safety and efficacy of immediate postpartum intrauterine 
IUCD were inserted 60 after vaginal delivery and 60 intracaesarean insertions was done. Out of 120 patients 48 $(40 \%)$ patients (23 vaginal, 25 caesarean) were ages between 20 to 30 years, $56(46.7 \%)$ patients (28 vaginal, 28 caesarean) had ages 31 to 40 years and $16(13.3 \%)$ patients (9 vaginal, 7 caesarean) had ages above 40 years. We found that most of the patients were ages above 25 years and was willing for IUCDs. These results shows similarity to some other studies in which the most common age group of patients regarding IPPIUCDs was 25 to 35 years.[13,14] In our study we found that most of the patients $68.3 \%$ had urban residency while $31.7 \%$ patients had rural residency. Many of studies shows similarity to some previous studies in which women had urban residency were more likely interested in family planning and use of IUCD.[15,16]

At 6 months follow-up we found no case of perforation and no case of pregnancy. Many of previous studies demonstrated $0 \%$ of pregnancy after insertion of IUCDs.[17] In present study 76 (63.3\%) patients had no complaint regarding IUCDs. Menstrual disturbance reported in $20(16.7 \%)$ patients in which $12(10 \%)$ patients belong to vaginal group and $8(6.7 \%)$ patients had intra-caesarean insertions. Pelvic pain was reported in $13(10.83 \%)$ patients (7 vaginal, 6 caesarean). A study conducted by Shukla et al.[18] using $\mathrm{Cu}$ T 200 B in immediate post-partum period, $27.23 \%$ women were found to have heavy bleeding during menstruation. Neither of the women in their study complained of pain in lower abdomen or abnormal vaginal discharge nor did any of them had any sign of PID.

In our study we found expulsion rate was 59 (7.5\%). Incidence of expulsion was high in vaginal group 6 (5\%) than the intra-caesarean insertion $3(2.5 \%)$ p value $<0.05$. Removal was done in $14(11.7 \%)$ cases (9 vaginal 5 caesarean) rate of removal of IUCD was high in vaginal group $p$-value $<0.05$. 4 patients want removal due to personal reasons, 4 patients had removal due to infection and 6 patients want removal due to abnormal vaginal discharge or irregular bleeding. Multiple previous studies was comparable to our study in which expulsion rate was 5 to $5.50 \%$ and removal rate was 10 to $20 \%$.[19] Other studies using CuT-380A have reported IUCD removal due to bleeding/pain as $6 \%$ to $8 \%[20,21]$. Difference in types of IUCD could possibly explain the different rates of bleeding problems. In our study the continuation rate at follow-up was $88.3 \%$. These results shows similarity to some previous studies in which continuation rate was 80 to $85 \%$.[22-23]

\section{CONCLUSION}

From the study results we came to the conclusion that PPIUCD is very effective, safe, and reversible contraceptive method which provides contraceptive effect soon after birth. Especially in those patients who have limited access to health care facilities and infrequent post partum care, this method can be considered as the best for them.

\section{REFERENCES}

1. Wasim T, Shaukat S, Javed L, Mukhtar S. Outcome of immediate postpartum insertion of intrauterine contraceptive device: experience at tertiary care hospital. $J$ Pak Med Assoc 2018; 68(4): 1-7.

2. Gupta A, Verma A, Chauhan J. Evaluation of PPIUCD versus interval IUCD (380A) insertion in teaching hospital of western U.P. Int J Reprod Contracept Obstet Gynecol 2013; 2(2): 204-08.

3. Asghar S, Hamayun A, Awan F. The future of postplacental intrauterine contraceptive device (PPIUCD) in Pakistan. Pak J Med Health Sci 2016; 10(1): 320-22.

4. Hofler LG, Cores S, Cwiak CA, Goedken P, Jamieson DJ, Kattke M. Implementing immediate postpartum long acting reversible contraception programs. Obstet Gynecol 2017; 129(2): 3-9.

5. Programming strategies for postpartum family planning [Sep;2019

];https://www.who.int/reproductivehealth/publications/family _planning/ppfp_strategies/en/ 2013

6. Canadian contraception consensus. Black A, Guilbert E, Costescu D. https://www.jogc.com/article/S17012163(16)30033-0/fulltext. J Obstet Gynaecol Can. 2015;37:936-938.

7. The efficacy of intrauterine devices for emergency contraception: a systematic review of 35 years of experience. Cleland K, Zhu H, Goldstuck N, Cheng L, Trussell J. Hum Reprod. 2012;27:1994-2000.

8. When can a woman have an intrauterine device inserted? A systematic review. Whiteman MK, Tyler CP, Folger SG, Gaffield ME, Curtis KM. Contraception. 2013;87:666-673.

9. Contraceptive use, intention to use and unmet need during the extended postpartum period. Ross JA, Winfrey WL. Int Fam Plan Perspect. 2001;27:20-27.

10. Immediate post-partum insertion of intrauterine devices. Grimes D, Schulz K, Stanwood N. Cochrane Database Syst Rev. 2010;5:0.

11. A facility birth can be the time to start family planning: postpartum intrauterine device experiences from six countries. Pfitzer A, Mackenzie D, Blanchard H. Int J Gynaecol Obstet. 2015;2:54-61.

12. Increasing use of postpartum family planning and the postpartum IUD: early experiences in West and Central Africa. Pleah T, Hyjazi Y, Austin S. Glob Health Sci Pract. 2016;2:140-152.

13. Iftikhar PM, Shaheen N, Arora E. Efficacy and Satisfaction Rate in Postpartum Intrauterine Contraceptive Device Insertion: A Prospective Study. Cureus. 2019;11(9):e5646. Published 2019 Sep 13. doi:10.7759/cureus.5646

14. Nadia Arif, Bushra Zafar, Raja Qaseem Ahmed, Farrukh Shehzad. A STUDY ON THE COMPARISON OF SAFETY AND Efficacy of post partum intrauterine contraceptive device (PPIUCD) with interval intrauterine contraceptive device. Pak Armed Forces Med J 2020; 70 (5): 1419-23

15. Hall JA, Benton L,Copas A, StephansonJ.Pregnancy intention and pregnancy outcome: systematic review and meta-analysis. Matern Child Health J 2017; 21(3): 670-04.

16. Habib AM, Greenow RC, Naushaeen S, Soofi BS, Sajid M, Bhutta AZ, et al. Prevalence and determinacies of unintended pregnancies amongst women attending antenatal clinics in Pakistan. BMC Pregnancy Childbirth 2017; 30(1): 17-21

17. S. Kittur and Y. M. Kabadi, "Enhancing contraceptive usage by post-placental intrauterine contraceptive devices (PPIUCD) insertion with evaluation of safety, efficacy and expulsion," International Journal of Reproduction, Contraception, Obstetrics and Gynecology, vol. 1, pp. 2632, 2012.

18. Postplacental intrauterine device insertion -- a five year experience at a tertiary care centre in north India. Shukla M, Qureshi S, Chandrawati Chandrawati. https://www.ncbi.nlm.nih.gov/pmc/articles/PM C3510889/ Indian J Med Res. 2012;136:432-435. 
19. Clinical outcomes of early postplacental insertion of intrauterine contraceptive devices. Celen S, Moroy $\mathrm{P}$, Suvak A, Aktulay A. Contraception. 2004;69:279-282

20. The efficacy of intrauterine devices for emergency contraception: a systematic review of 35 years of experience. Cleland K, Zhu H, Goldstuck N, Cheng L, Trussell J. Hum Reprod. 2012;27:1994-2000

21. Nahar KN, Fatima P, Dewan F, Yasmin A, Laila TR, Begum $N$ et al. Accetibility and feasibility of postpartum intrauterine contraceptive device insertion in Bangabandhu
Sheikh Mujib Medical university, Dhaka, Bangladesh. Bangladesh Med J 2018; 47(3): 25-30.

22. Nayak AK, Jain MK. Experience on awareness, acceptability, safety, efficacy, complications and expulsion of post-partum intrauterine contraceptive device insertion. Int J Sci Stud 2017; 5(1): 207-12

23. Heller R, Johnstone A, Cameron ST. Routine provision of intrauterine contraception at elective cesarean section in a national public health service:a service evaluation. Acta Obstet Gynecol SC 2017; 96(1): 1144-51 